\title{
Effectiveness of urban transport modes
}

\author{
Agata Pomykala, ${ }^{1, *}$ \\ ${ }^{1}$ Research Railway Institute, ul. Chłopickiego 50, 04-274, Warsaw, Poland
}

\begin{abstract}
Social expectations in terms of improving the conditions of life in cities whilst increase of mobility poses a difficult challenge for urban transport organizers. At the same time, conditions related to sustainable development policies with scarce resources and available reserves focus attention on transport optimization and reduction of environment harmful impacts. The paper presents an assessment of the efficiency of urban transport in terms of capacity, energy use, $\mathrm{CO}_{2}$ emissions and costs, based on data on European medium cities in traffic conditions - peak (congestion) and off-peak traffic (no congestion). Compared were road vehicles: cars and buses of different propulsion, motorcycles and also rail vehicles: metro, tram/light rail and trains/heavy rail. The results are presented in tables or in graphs. The comparisons make it possible to identify the most efficient, in various scenarios, transport modes and may be helpful in deciding on issues related to the provision and organization of urban transport. In this article, cost evaluation omits external costs (although $\mathrm{CO}_{2}$ emissions are taken into account) but includes fixed and variable costs associated with the use of vehicles (including fuel costs, maintenance, inspections, depreciation, insurance).In the preparation of the article information available in literature, publication and reports, particularly of the European Commission one was used.
\end{abstract}

\section{Introduction}

Nowadays, the necessity to solve problems related to urban and agglomeration transport is becoming more and more important. Cities generating significant benefits for the development of the economies of the regions at the same time face problems of high population density, congestion and excessive pollution. Already, $64 \%$ of all kilometres travelled relate to daily individual travels in the urban environment, and it is expected that their length will triple by 2050 . It is anticipated that by 2050 , the time spent in traffic jams by one inhabitant will be doubled and will be 106 hours [1]. Increasing avalanche mobility concerns cities to a greater extent than rural areas. Inhabitants of European cities already constitute more than $70 \%$ of Europeans and, according to forecasts, the number of inhabitants of urban areas by 2030 will exceed $80 \%$ of the European population, exacerbating related the problems $[2,3]$. The congestion, whose cost in European urban areas is valued at EUR 100 trillion, in a particularly negative way in the area of cities affects the functioning of society and the economy [4]. Nearly $70 \%$ of road accidents occur in them, and in cities the most noticeable is the impact of transport on environmental pollution: $70 \%$ of pollutants emitted in transport are generated in them and $40 \%$ of total $\mathrm{CO}_{2}$ emitted by road transport. [5]. Awareness of the negative impact of transport on the environment, including health and quality of life, but also climate change and the associated threat to biodiversity is reflected in the concept of sustainable transport and influences the emergence of local organizations interested in transport policy. The development of mobility in accordance with the principles of sustainable development is one of the most important challenges for the cities of the future.

Transport needs of residents of modern cities can be satisfied in various ways, using various means of transport: individual or collective. Already today, there are significant differences in this respect: for example, in Vienna, $75 \%$ of commuting to work is carried out using public means of transport, while in Palermo or Antwerp less than $30 \%$ [6]. Decisions on the choice of means of transport are made by the citizens on the basis of various criteria, both objective and subjective, and the task of the city authorities is to create incentives to use the means of transport most conducive to the fulfilment of the development policy. Currently, it is important to take into account not only social expectations in terms of air cleanliness or health protection, but also sustainable urban development. On the one hand, it is expected to meet the ever-increasing mobility needs, including convenience, short travel time and low cost, and on the other: reduce nuisances related to excessive concentration of people and negative effects of transport on the natural environment and living conditions and ensure even growth socio-economic development. Decisions regarding transport systems in cities should take into account not only current transport needs but also, in accordance

\footnotetext{
*Corresponding author: a.pomykala@infotransport.pl
} 
with the assumptions regarding the transport function as an integrator of socio-economic life, also issues related to spatial planning and shaping the functional and operational structure. Knowledge of the advantages and disadvantages of transport means is necessary especially in the context of the socially understood need to consider the concept of its sustainability. Analysis of the effectiveness of means of transport can be a starting point for the development of transport services in the city, including the social striving to protect and improve the quality of life. The aim of the article is to indicate the effectiveness of individual means of transport to facilitate decision making regarding their use and affecting the improvement of living conditions in the urban environment.

\section{Effectiveness}

The increasing importance of transport in social and economic life requires its evaluation not only from a technical and organizational point of view but also in terms of macroeconomic efficiency of the entire system, i.e. ensuring effective implementation of the need to move both goods and people. Due to the complexity of the relationship between this sector and the socioeconomic system, there is a need for a holistic view that takes into account the functionality of the entire system and not only its separate elements. Assuming that the transport system is a system of technical, organizational and human means related to each other in such a way as to efficiently carry out the movement of persons or (i) loads in time and space [7] and taking into account the expectations regarding the optimization and sustainability of transport development, it is necessary to consider the issues of efficiency in its planning. Effectiveness is an ambiguous term used in various disciplines of science. This word derives from: Latin effectivus, ,practical", equivalent to effect(us) "productive, effective," from effect-, stem of efficere [8]. Microeconomic efficiency focuses on the functioning of the business unit and its operations, including investment. It reflects the benefits of this activity. According to the principle of rational management, they should be adequate to the expenditures incurred, understood as the degree of consumption of production factors in the process of implementing an economic undertaking. The increase in efficiency can be implemented in two ways:

- maximization of effects, i.e. obtaining a higher level of effects at a constant level of expenditure,

- minimizing expenditures, i.e. achieving certain economic effects while reducing expenditures [9].

Efficiency in transport is understood as the mutual relation between the consumption of natural resources and the costs generated on the one hand, and the benefits resulting from their use on the other. Transport costs are most often understood as those incurred by users and carriers. It sometimes happened that external costs incurred by the general public, for example costs of accidents or environmental impact were omitted in the assessment of transport efficiency. With the development of the concept of sustainable transport, it is required to consider external costs in cost-benefit analyses.
Efficiency is best understood in terms of social and environmental integration and in contrast to economic, production and financial efficiency, regulated by the "invisible hand of the market" requires institutional adjustment of the market mechanism through sectoral policy actions integrated with environmental policy [10].

\section{Factors affecting the choice of a means of transport}

The choice of mode of transport is dictated by both economic and technical conditions. Analysing the factors that influence the planning of the mode of a city transport the problem was considered in the following aspects:

- accessibility of space (transport capacity for particular means of transport with the assumed occupancy of the area);

- time to move around the city in various relations (directions);

- environmental performance of the mode of transport (degree of environmental impact);

- unit cost of transport in the aspect of the entire system (total infrastructure, vehicle and external costs).

\section{Characteristics of modes of transport}

In the assessment of urban means of transport, listed in Table 1 the following parameters have been accepted for comparison:

- capacity - defined in terms of passengers per vehicle and passengers per hour in relation to infrastructure capacity;

- energy use - defined in terms of MJ per passkm;

- $\mathrm{CO}_{2}$ emissions - defined in terms of $\mathrm{CO}_{2}$ per passkm;

- cost - defined in terms of EUR per passkm.

Indicators have been calculated in relation to scenarios for a medium city (according to OECD 200,000500,000 habitants) in the conditions of:

- congested peak traffic;

- un-congested off-peak traffic.

Table 1. Urban transport modes comparison [11, p.3].

\begin{tabular}{|l|l|}
\hline \multicolumn{1}{|c|}{ Transport mode } & \multicolumn{1}{c|}{ Fuels } \\
\hline \multirow{2}{*}{ Passenger car } & $\begin{array}{l}\text { Petrol } \\
\text { Diesel } \\
\text { Gas (CNG, LPG) } \\
\text { Hybrid Electric (petrol } \\
\text { only) } \\
\text { Battery electric }\end{array}$ \\
\hline Motorcycle, Moped & Petrol \\
\hline Bus: Midi, Large, Bus Rapid & $\begin{array}{l}\text { Diesel } \\
\text { Gas (CNG) } \\
\text { Transit (BRT) }\end{array}$ \\
& $\begin{array}{l}\text { Hybrid electric (diesel) } \\
\text { Battery electric }\end{array}$ \\
\hline $\begin{array}{l}\text { Rail: Tram/Light Rail (LTR) } \\
\text { Metro,Heavy rail }\end{array}$ & $\begin{array}{l}\text { Electric } \\
\text { Diesel (Heavy rail only) }\end{array}$ \\
\hline
\end{tabular}

The theoretical capacity, of each mode of transport, has been determined mainly on the basis of the physical infrastructure characteristics,' real capacity 'corresponds 
to the Community understanding of this concept in the context of urban transport, which means defining capacity as the number of passengers who are transported per unit of time transport, as shown in Tab.2, different factors, marked "+", affect their value.

\subsection{Private cars}

In the case of passenger cars, the theoretical capacity results from the vehicle's capacity and the capacity of the road infrastructure. The vehicle capacity assumed for the analysis is 5 passengers, and the capacity of the road infrastructure depends on the road characteristics. For the purposes of this task, the reference value for urban capacity in terms of vehicle traffic per hour was adopted at 4500 pass / hour (in acc. with the Technical Note 10 Transport Transport for London's Roads Task Force, defining the values for different types of city roads).

Table 2. Capacity of urban transport modes affecting factors (self-study, based on [11, p.5]).

\begin{tabular}{|c|c|c|c|c|c|c|c|}
\hline \multirow[b]{2}{*}{ 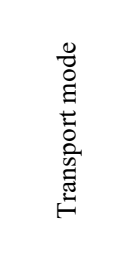 } & \multirow[b]{2}{*}{ 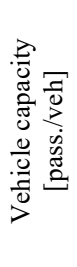 } & \multicolumn{3}{|c|}{ Theoretical capacity } & \multicolumn{3}{|c|}{ Actual capacity } \\
\hline & & 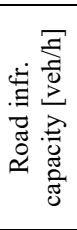 & 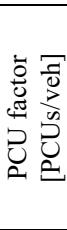 & 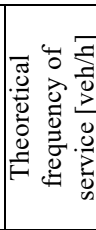 & 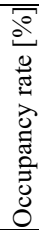 & 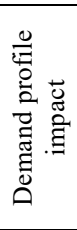 & 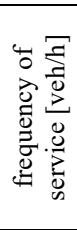 \\
\hline Private car & + & + & & & + & + & \\
\hline Motorcycle & + & + & + & & + & + & \\
\hline Bus & + & & & + & + & & + \\
\hline Rail * & + & & & + & + & & + \\
\hline
\end{tabular}

* Rail: Tram, Metro, Light Rail, Heavy Rail

\subsection{Mopeds and motorcycles}

Mopeds and motorcycles are treated similarly to cars, however their transport capacity is limited to one or two passengers and they also take up less space on the road. Theoretical capacity is the result of the maximum number of passengers, road infrastructure capacity and coefficient of equivalence of vehicles in terms of PCU. As the assumed maximum number of passengers, two passengers were accepted for the motorcycle, and for the moped - one passenger. The reference value for urban capacity is the same as for cars, i.e. 900 PCU per hour. The vehicle utilization rate in the EU-28 is 1.1 passenger per motorcycle, i.e. around $55 \%$ of the vehicle's capacity. The average number of passengers on a motorcycle was estimated on the basis of the TRACCs database and statistics of selected countries [11 p. 7].

\subsection{Buses}

The following vehicle capacity was assumed for the calculation of the theoretical carrying capacity:

- Midi bus (lenght:10 m): 60 passenger per vehicle

- Large bus (lenght:12 m): 100 passenger per vehicle

- BRT(lenght:18 m): 140 passenger per vehicle.

For the actual capacity, the service frequency was additionally taken into account.
Table 3. Road transport modes capacity comparison (self-study, based on [11, p.5-10]).

\begin{tabular}{|c|c|c|c|}
\hline 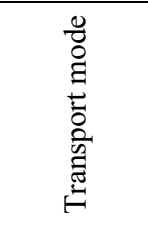 & 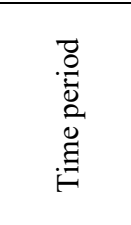 & 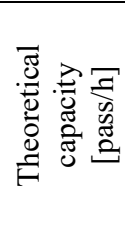 & 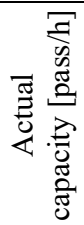 \\
\hline \multirow{2}{*}{ Car } & Peak & \multirow{2}{*}{4500} & 1530 \\
\hline & Off-peak & & 920 \\
\hline \multirow{2}{*}{ Motorcycle } & Peak & \multirow{2}{*}{3600} & 1980 \\
\hline & Off-peak & & 1180 \\
\hline \multirow{2}{*}{ Moped } & Peak & \multirow{2}{*}{1800} & 1800 \\
\hline & Off-peak & & 1080 \\
\hline \multirow{2}{*}{ Midi bus } & Peak & \multirow{2}{*}{1200} & 270 \\
\hline & Off-peak & & 20 \\
\hline \multirow{2}{*}{ Large bus } & Peak & \multirow{2}{*}{2000} & 600 \\
\hline & Off-peak & & 200 \\
\hline BRT & Peak & 2800 & 1800 \\
\hline
\end{tabular}

\subsection{Rail}

For urban rail transport capacity is theoretically a matter of vehicle infrastructure and capacity. In reality, the occupation is less than $100 \%$, and the frequency of the service is usually lower than the theoretical maximum frequency. Therefore, in order to estimate the theoretical transport capacity, the frequency of services and vehicle capacity were taken into account, using the same approach as for road (bus) transport [11 p. 10-12]. With regard to vehicle capacity, the following:

- Tram/Light rail: 170 pass/veh;

- Metro: 550 pass/veh;

- Heavy rail: 1000 pass/veh.

Table 4. Rail transport modes capacity comparison (self-study, based on [11, p.12]).

\begin{tabular}{|c|c|c|c|}
\hline 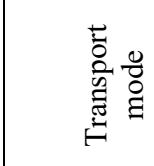 & 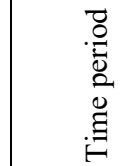 & 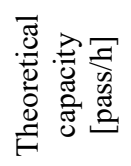 & 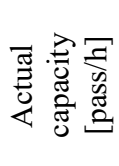 \\
\hline \multirow{2}{*}{ Tram/LTR } & Peak & \multirow{2}{*}{3400} & 1150 \\
\hline & Off-peak & & 480 \\
\hline \multirow{2}{*}{ Metro } & Peak & \multirow{2}{*}{16500} & 5690 \\
\hline & Off-peak & & 2200 \\
\hline \multirow{2}{*}{ Heavy rail } & Peak & \multirow{2}{*}{15000} & 2250 \\
\hline & Off-peak & & 400 \\
\hline
\end{tabular}

\section{Transport capacity comparison}

The comparison of urban modes transport in terms of transport capacity indicates (Fig. 1), taking into account the theoretical aspect, the advantage of metro and trains. The smallest capacity is characterized by medium-sized buses.

The actual situation is different due to realignment of vehicle occupancy and consideration of differences in peak and off-peak hours (Fig. 2). 


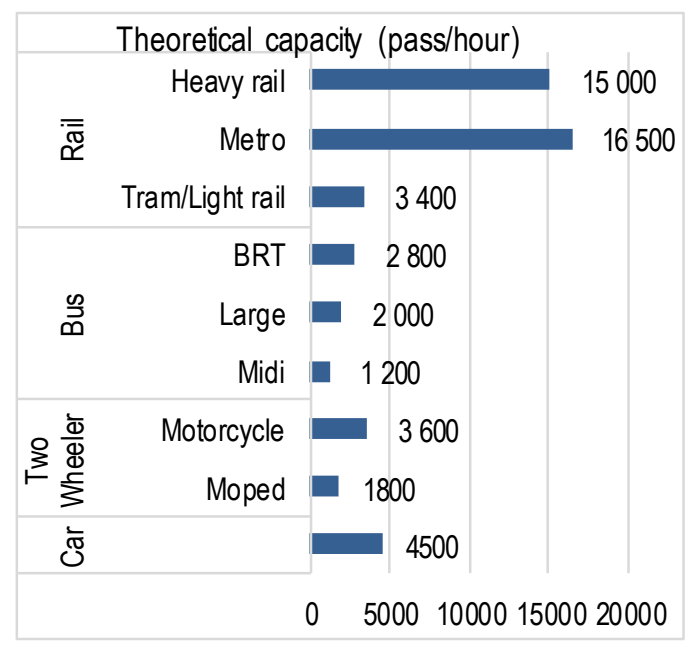

Fig. 1. Theoretical capacity (passenger/hour) in a medium city (self-study, based on [11, p.13]).

At peak times, collective transport provides greater efficiency than an individual, while in off-peak periods it is the reverse.

\section{Energy consumption and $\mathrm{CO}_{2}$ emis- sions comparison}

Energy consumption and $\mathrm{CO}_{2}$ emissions are closely related measures that are used to assess the environmental performance of transport. Average energy consumption calculated for four urban passenger transport means (cars, two-wheelers, buses and rail vehicles) was presented in megajoules per passenger kilometre (MJ / pkm), according to the WTW (well-to-wheel method, analysis from the source of energy carrier). This is representative data for transport systems throughout the EU. $\mathrm{CO}_{2}$ emissions per kilometre were determined based on the results of energy consumption using coefficients of

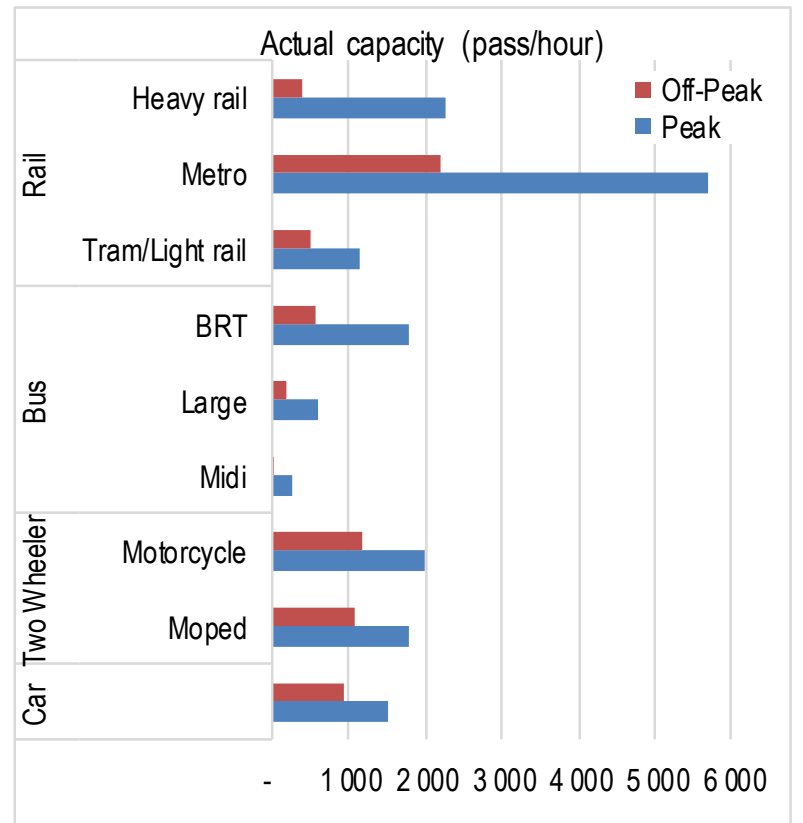

Fig. 2. Actual capacity (passenger/hour) in a medium city [11, p.16].

$\mathrm{CO}_{2}$ emissions related to both direct (fuel combustion) and indirect (fuel production) emissions. Comparison of the average WTW $\mathrm{CO}_{2}$ emission is shown in Fig.3

The energy consumption in individual means of transport depends mainly on the type of propulsion and speed of movement (off-peak or peak traffic). During peak hours, the estimated average speed is $30 \mathrm{~km} / \mathrm{h}$. Vehicle occupancy rates are assumed to be the same at both rush hour and away times, so they do not affect the results. Comparison of the average energy consumption by time period and modes of transport is shown in Fig. 4.

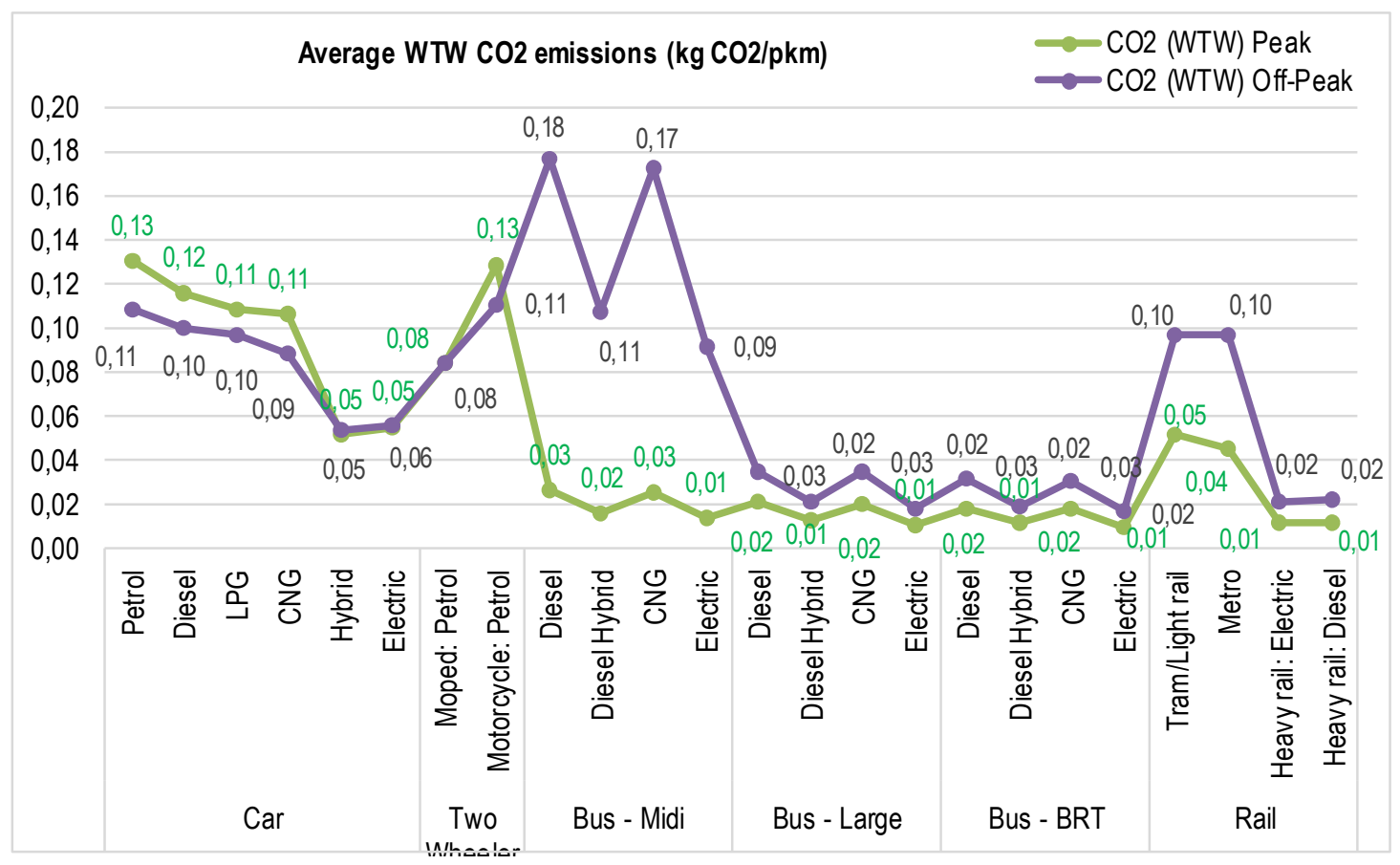

Fig. 3. Comparison of the average $\mathrm{WTW} \mathrm{CO}_{2}$ emission in medium city (self-study, based on [11 p.31]). 


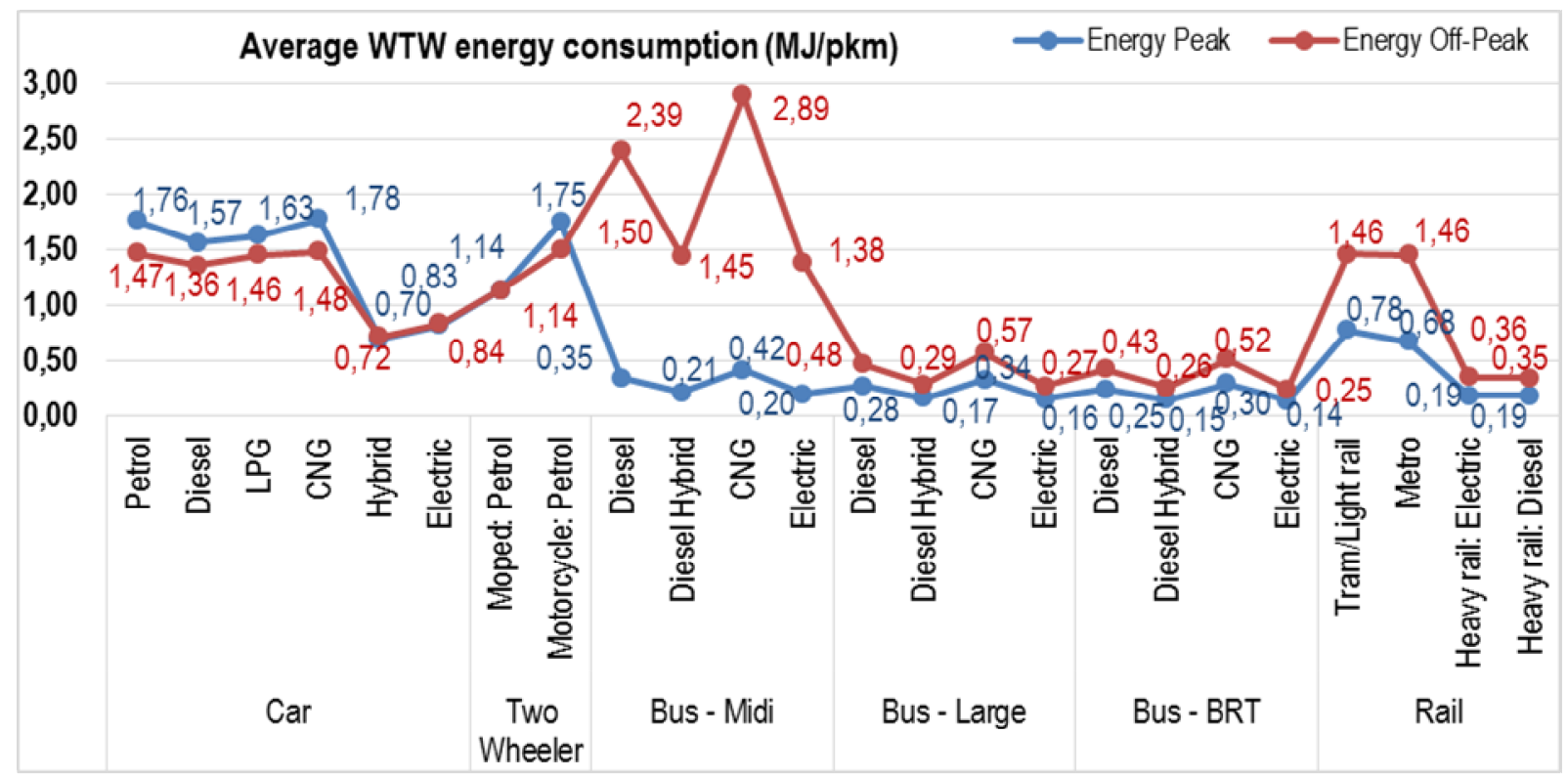

Fig. 4. Comparison of the average WTW Energy consumption in medium city (self-study, based on [11 p.31]).

\section{Costs comparison}

For compare of cost calculated the cost of transporting one passenger per passenger kilometre in different modes of urban transport [11, pp. 33-44]. The assessment of costs is related to their constituent elements considered in aspects:

- costs incurred by the customer (for public transport fares/ tariffs)

- costs incurred by the service provider - not included in the tariff

- social costs (external costs).

In this paper, the cost assessment omits external costs (although the comparison of $\mathrm{CO}_{2}$ emissions is presented above), but takes into account fixed and variable costs related to the operation of vehicles (including costs related to fuel consumption and maintenance, inspections, depreciation, insurance).

\subsection{Energy cost}

The average energy cost in individual vehicle categories has been estimated based on the result of energy consumption estimation (with appropriate conversion factors) in combination with European averages. Energy costs for passenger cars in medium cities vary depending on the type of drive between $0.028 \mathrm{EUR} / \mathrm{vkm}$ for electric cars in peak hours (0.029 EUR / vkm - off-peak hours), hybrid cars - 0.044 EUR / vkm during peak hours and 0.045 EUR / vkm for off-peak time up to 0.111EUR / vkm in peak hours (0.093 EUR / vkm off-peak) for petrol cars [11, p.34]. The energy costs for single-track vehicles are respectively for motorcycles in rush hour 0.071 EUR / vkm, off peak - 0.61 EUR / vKM, and for mopeds - 0.042 EUR / vkm regardless of the time of day. Other fixed and variable cost (not energy related)

The cost analysis includes other costs: purchase, maintenance, amortisation, ownership taxes and insurance those make up the costs of producing/delivering a service. For public modes of transport, additional costs of remuneration and fixed costs are included. The costs of providing transport services in cities depend on local conditions (e.g. commercial speed). For medium and large buses, the same costs of service delivery were assumed, and BRT buses were treated separately. For the public transport rail service, all elements that make up the cost of producing and delivering the service have been included (even if they are not covered by the tariffs), as well as for road. Tab. 5 contains information on the costs of service production broken down by modes of public transport.

Table 5. Average total production cost (self-study, on based [11 p.41, 43]).

\begin{tabular}{|l|l|c|}
\hline $\begin{array}{l}\text { Transport } \\
\text { mode }\end{array}$ & Fuel type & $\begin{array}{c}\text { Average total produc- } \\
\text { tion cost [EUR/vkm] }\end{array}$ \\
\hline \multirow{4}{*}{ Midi bus } & Diesel & 3.52 \\
\cline { 2 - 3 } & Diesel hybrid & 3.42 \\
\cline { 2 - 3 } & CNG & 3.52 \\
\cline { 2 - 3 } & Electric & 3.44 \\
\hline \multirow{4}{*}{ Large bus } & Diesel & 3.77 \\
\cline { 2 - 3 } & Diesel hybrid & 3.64 \\
\cline { 2 - 3 } & CNG & 3.77 \\
\cline { 2 - 3 } & Electric & 3.67 \\
\hline \multirow{4}{*}{ BRT } & Diesel & 4.55 \\
\cline { 2 - 3 } & Diesel hybrid & 4.36 \\
\cline { 2 - 3 } & CNG & 4.52 \\
\cline { 2 - 3 } & Electric & 4.35 \\
\hline \multicolumn{2}{|l|}{ Tram/light rail } & 5.7 \\
\hline \multicolumn{2}{|l}{ Metro } & 14.2 \\
\hline \multicolumn{2}{|l}{ Heavy rail } & \multicolumn{2}{|c|}{} \\
\hline
\end{tabular}

For comparison of the transport costs of one passenger per kilometre in different modes, both individual and public, both the theoretical point of view and the actual situation resulting from the occupancy of vehicles, the speed achieved and the capacity of the infrastructure were taken into account. A comparison of the theoretical costs of urban means of transport indicates two-wheeled vehicles as the most expensive (0.15-0.20 EUR / paskm) and trains as the cheapest (0.02 EUR / paskm) regardless 
of the traffic conditions. A comparison of actual costs gives a completely different picture that varies depending on the time of day (traffic situation). During peak hours, individual modes of transport are characterized by the highest average cost per passenger-kilometre ( 0.15 to 0.26 EUR / paskm). The lowest average cost is characterized by trains (EUR 0,02/ pkm), BRT buses and large buses (about EUR 0,04 / paskm). The average bus costs are also relatively low (0.07 EUR / paskm). In off-peak hours, the actual costs are doubled, the most expensive is the medium-sized bus, which costs up to 0.5 EUR / paskm. As a result, the difference between the cost of individual and public transport decreases, although the train is still the lowest cost.

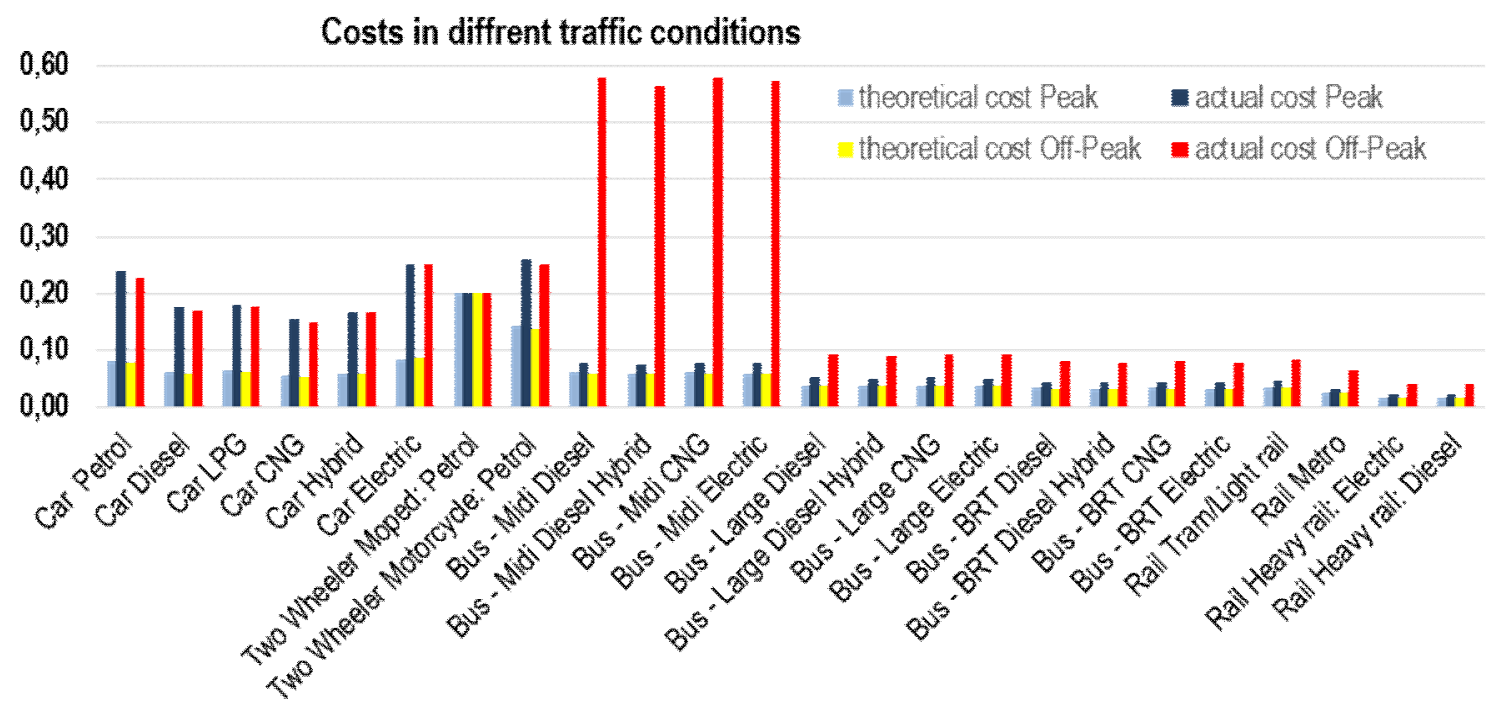

Fig. 5. Comparison of theoretical and actual costs in differential traffic conditions (self-study, based on [10 p. 46]).

\section{Summary}

The assessment of competitiveness of urban transport modes in the aspects of capacity, energy consumption, $\mathrm{CO}_{2}$ emissions and costs was carried out on the basis of data on the medium size of European cities, taking into account changes resulting from the traffic volume, i.e. peak traffic (congestion) and off-peak traffic (without congestion). The paper were used the calculations and information contained in the report published in 2017 by the European Commission.

The effectiveness of public transport depends on a number of factors, such as infrastructure capacity and transport means capacity, the level of occupancy in vehicles and operation conditions. In addition, the assessment of the transport modes differs depending on what conditions and parameters are taken into account. Taking into account the different urban conditions, several key trends are noticeable:

1. In peak periods, capacity, costs and environmental performance per passenger in public transport is generally better than in case of individual transport. However, at off-peak hours, the effectiveness of the modes is more complex for them and its results may differ than for peak periods.

2. In general, in all conditions, costs are lower in public transport than in individual transport.

3. Overall infrastructure and transport means capacity for vehicles is the highest in rail transport systems. In the case of road transport, the capacity of individual and public transport (buses), in periods beyond the peak is comparable, and even due to the low level of occupancy rate in public transport, sometimes it is higher for cars.

4. Energy consumption and $\mathrm{CO}_{2}$ emissions per passenger are generally lower for public transport during peak hours, although the metro and light rail systems are relatively energy-intensive. However, during offpeak periods, individual transport is characterized by lower energy consumption and lower $\mathrm{CO}_{2}$ emissions per passenger.

5. In general, all transport modes play their part in an effective urban transport system. Public transport should be basic during peak hours, with rail transport providing the highest capacity for the most busy routes. To improve the environmental performance of public transport systems, electric and hybrid systems should be preferred. Individual transport modes play a special role in off-peak periods when there are not enough passengers to ensure a high rate of occupancy in public transport. Effectiveness data can be used by cities to optimize the organization of urban transport.

\section{References}

1. ARTHUR D. LITTLE \& UITP, The Future of Urban Mobility 2.0, (January 2014)

2. Urban Europe - statistics on cities, towns and suburbs - executive summary, (Data extracted in February-April 2016), http://ec.europa.eu/eurostat/statisticsexplained/index.php/Urban_Europe_- 
_statistics_on_cities, _towns_and_suburbs__executive_summary [acces:15.08.17]

3. United Nations, World Urbanisation Prospects: The 2014 Revision, (New York, 2015)

4. T. Dyr, and M. Kozlowska, Congestion costs in the European Union, Technika Transportu Szynowego, tts, 7-8, 18-23 (2017) [In Polish]

5. European Commission, Urban mobility, https://ec.europa.eu/transport/themes/urban/urban_m obility_en [access: 01.09.17]

6. European Commission, Statistics on European cities, http://ec.europa.eu/eurostat/statisticsexplained/index.php/Statistics_on_European_cities [access: 01.09.2017]

7. M. Jacyna, Modeming and evaluation of transport systems, (Oficyna Wydawnicza Politechniki Warszawskiej, Warszawa 2009) [In Polish]
8. Douglas Harper, Online Etymology Dictionary (2010), http://www.dictionary.com/browse/effectiveness

9. T. Dyr, and P.R. Kozubek, Evaluation transport infrastructure investments financed by European Union funds, (Instytut Naukowo-Wydawniczy ,SPATIUM”, Radom, 2013) [In Polish]

10. B. Pawłowska, Sustainable transport development against the background of contemporary socioeconomic processes, (Wydawnictwo Uniwersytetu Gdańskiego, Gdańsk, 2013) [In Polish]

11. European Commission, Study on urban mobility Assessing and improving the accessibility of urban areas. Annexe 3: Task 3 Report-Relative efficiency of urban passenger modes, (Brussels, 2017) 